\title{
NEURAL NETWORK-BASED APPROACH FOR DETECTION AND MAGNITUDE DETERMINATION OF TURN FAULTS IN INDUCTION MOTORS
}

\author{
M. Alaam, M. Abdelkariem, M. A. Elkhazendar \\ Department of Electrical Power and Machine Engineering, \\ Faculty of Engineering, Tanta University, Tanta, Egypt
}

\begin{abstract}
This paper presents a novel scheme for the detection and magnitude determination of turn faults. Artificial neural network (ANN) plays a role as fault detector and fault location estimator. This study is based on simulating the faulty motor on phase (abc) frame. Insensitivity of the technique to load variation, supply voltage variation and unbalance in supply voltage is illustrated in this paper. The results from this study suggests that the proposed method provides a powerful and a general.approach to the ANN based fault detection.

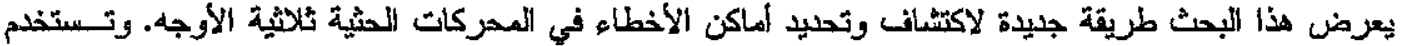

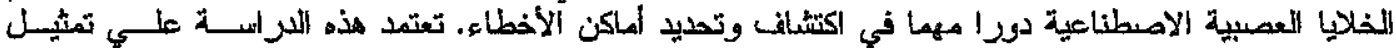

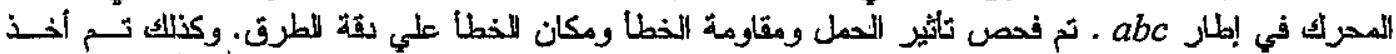

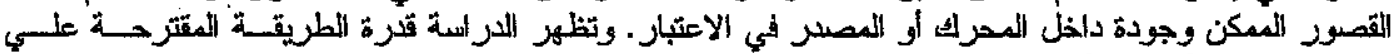
اكتشاف وتحليد أماكن الأخطاء.
\end{abstract}

Keywords: Induction motor, Neural network, Turn fault detection.

\section{INTRODUCTION}

Stator faults are one of the most common electrical faults in induction motors. Moreover, most of these faults start as an inter-turn short circuit in one of the stator coils [1]. During this time, the temperature in the short circuit exceed the breakdown temperature of the insulation [2]. The increased heat due to this short circuit will eventually cause turn to turn or turn to ground faults, and finally lead to a breakdown of the stator [3]. The time, from an inter-turn short circuit occurrence to breakdown of the stator, can be as small as 1 to $2 \mathrm{sec}$.

Researches [4-9] have been done and various schemes have been presented for on-line detection of turn faults at their earliest stage. Although the schemes presented, generally have the advantage of being real-time solutions, fionie of them deals with the magnitude of the fault; or' ix other words, the number of short turns: Also, due to the simplified model used, or due to the implementation difficulties, they have some limitations, even in the detection of turn faults. Some of them are not valid under various possible operating conditions of the machine, such as variation in load, supply voltage and temperature, unbalanced supply voltage and inverter supplies. Some others require experimental data, collected for each specific motor, under artificial faults and/or from fault-free motor, which make them impractical.
A novel scheme, for turn fault detection, based upon neural network is presented. By using this technique, in addition to fault detection, the exact location of the fault is also determined.

ANN-based turn fault detection schemes may be based on supervised learning neural networks [10] and unsupervised learning neural networks [11]. In [11], the effective negative sequence impedance is used as an indicator of a turn fault and the neural network is trained on inputs from a healthy machine only; however, this scheme ignores the effects of unbalanced supply voltages and would not reliably monitor the condition of machines with significant inherent asymmetries. Supervised-learning neural networks require for training, a desired output vector for each input vector. The learning algorithm updates the network weights to minimize the error between the estimated and desired output. Hence, the network learns the complex mathematical model of the system, with non-idealities in the machine and instrumentation included. On the other hand, unsupervised learning neural networks cluster data into different classes, like "healthy machine" or "machine with turn fault", based on the similarity of the input vectors; hence, they do not need output or target vectors for training. The Self-Organizing Feature Map (SOFM) is a popularly used unsupervised-learning neural network [12]. 


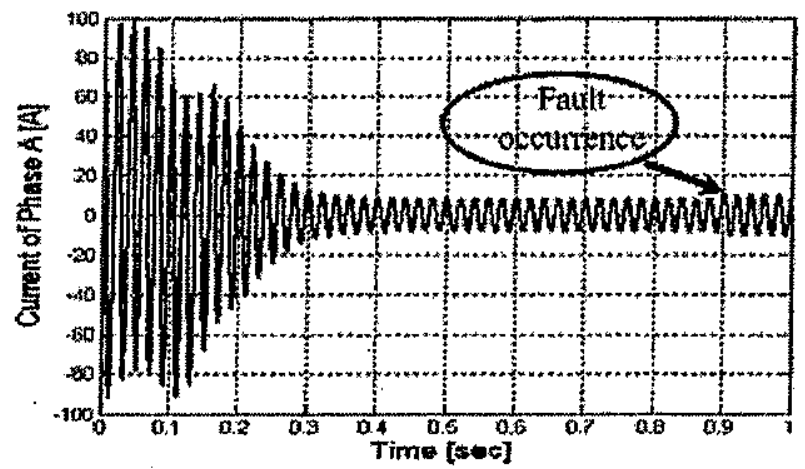

Fig. 1. The current waveform of phase $A$ for $5 \%$ of turns in phase $A$ short-circuited.

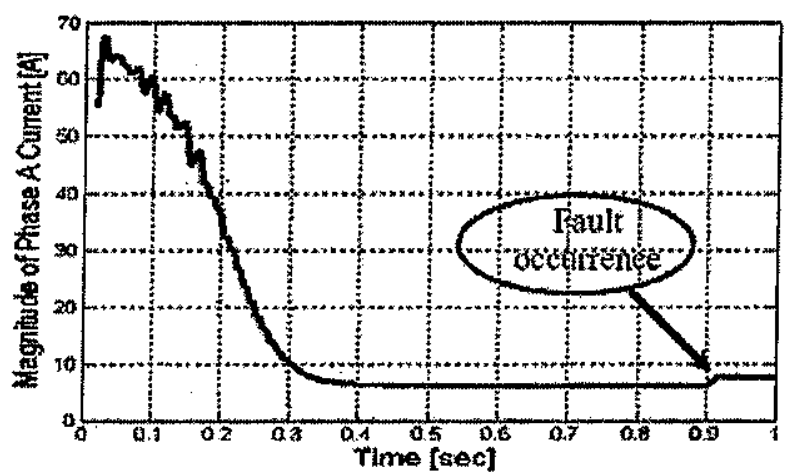

Fig. 2. The estimated amplitude of the fundamental frequency component of the phase $A$ current for $5 \%$ of turns in phase $A$ short-circuited

\section{ANN-BASED PROPOSED SCHEME}

The proposed scheme is shown in Fig. 3. The input current and voltage signals are extracted using one current transformer and one voltage transformer for each phase: These extracted signals are sampled with a sampling rate of 200 sample/cycle. The six sampling signals are fed to DFT filter. The DFT filter has been nominated among different digital filter routines, as the most dependable filter for relay implementation [14-15]. This filter is characterized with a maximum gain $\cdot$ at the frequency of the fundamental and zero gain for the dc and integer harmonics. But it is failed to remove the non-integer harmonics [16]. The output of DFT filter are the voltage and the current phasors for each phase. The magnitudes of these phasors are used as the input to the neural network.

The basic function of the ANN technique is to identify the hidden correlations between the input vector and the output, through training patterns obtained from several simulated health and fault cases, which may not be deduced otherwise. In order to deduce this correlation between inputs and output, the ANN is trained with typical healthy and faulty cases prior to the application stage.

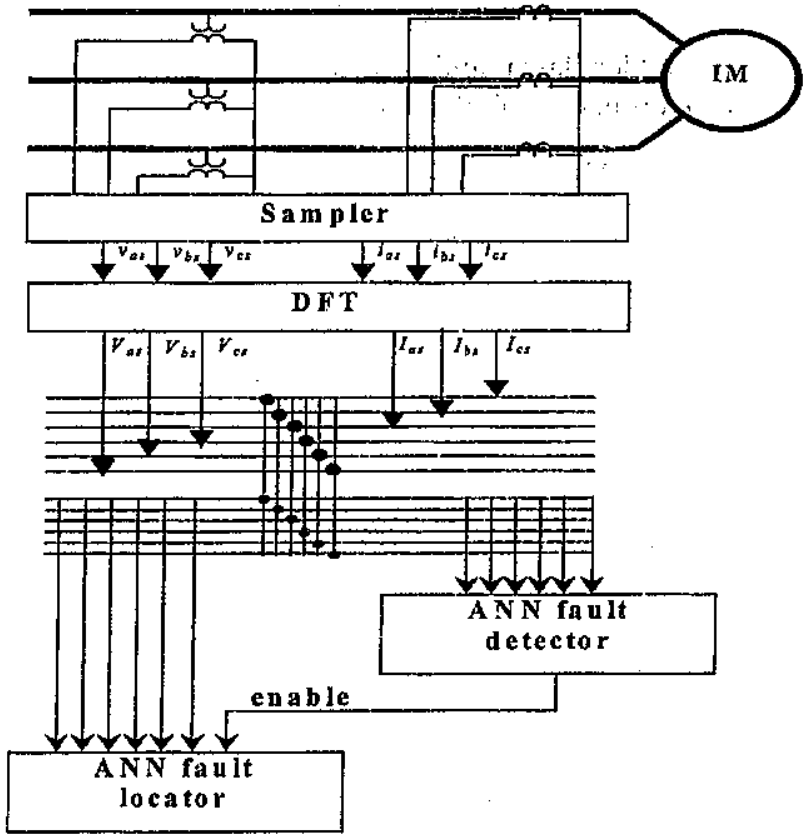

Fig 3. Schematic diagram of the proposed ANN technique.

The training cases include the different cases of internal faults in addition to the healthy conditions. Fault conditions are applied to cover all the possible winding faults. This is achieved by varying the percentage of the splitted windings, based on the internal fault simulation approach discussed in section II. Unbalance voltage supply variation is also studied and included in these cases.

Some 1023 internal fault cases are simulated. However, healthy cases are imposed by varying the load torque and supply unbalance to cover all possible loading conditions. Some 93 healthy cases are considered. The total collected cases sum up to 1116 including both healthy and faulty conditions. These cases are divided to be used for training and testing modes as given in tables 1 attached in the Appendix.

The proposed scheme consists of two stages. The first stage is used to detect the fault occurrence. The second stage is the fault location determination (i.e. the percentage of faulty turns). Each of these neural network stages is trained using different construction and training strategies to get the most accurate scheme. The most successful constructions of these networks are shown in Fig. 4 for fault detection and in Fig. 5 for fault location. Note that, there is no meaning to use fault location stage before fault detection stage gets high.

The fault detector net has six input neurons (magnitude of stator phase voltages and magnitude of stator phase currents), four hidden neurons arranged 
in one hidden layer and one neuron output whose value determine the fault occurrence.

The fault locator net has the same structure in input and hidden layers but has two differences. The first is the output of fault location is the location of fault as a percentage of faulty turns. The second difference is that the fault locator must be enabled from the output of fault detector.

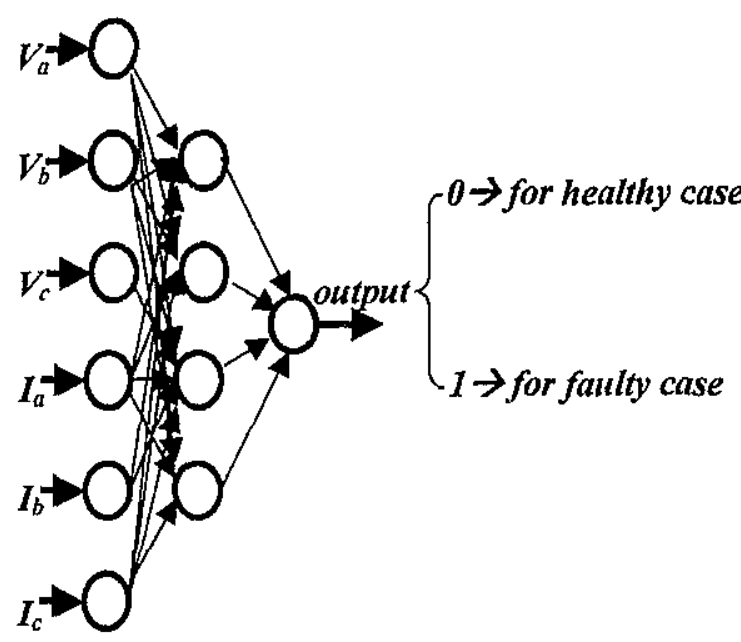

Fig. 4 The proposed fault detection net structure

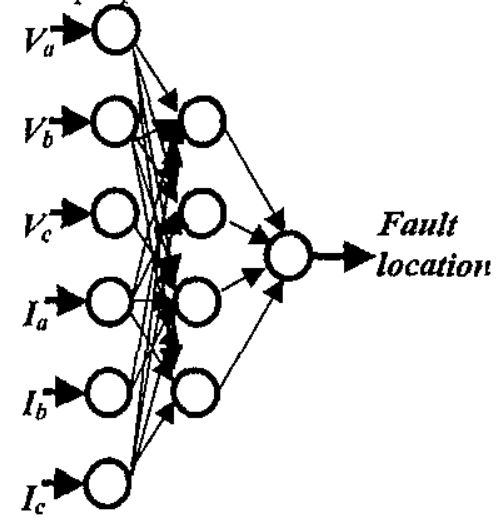

Fig. 5 The proposed fault location net structure

\section{EXPERIMENTAL SETUP}

The stator of 4-pole induction motor has been modified by addition of a number of taps connected to the stator coils, for each of the three phases, allowing for the introduction of short turns at several locations in the stator winding.

The experimental system scheme is shown in Fig. 6. AC contactor is used to introduce or remove shorted turns. Notice that a shorting resistor should be used, whose value is chosen appropriately, so as to create an effect strong enough to be measured, but simultaneously big enough to limit short-circuit current and thus protect the motor from complete failure. The stator three-phase voltage and current were sampled by high-frequency multi-channel data acquisition device, type NI - J'CI6013, and delivered to MATLAB 7.1 for thorough processing and analysis.

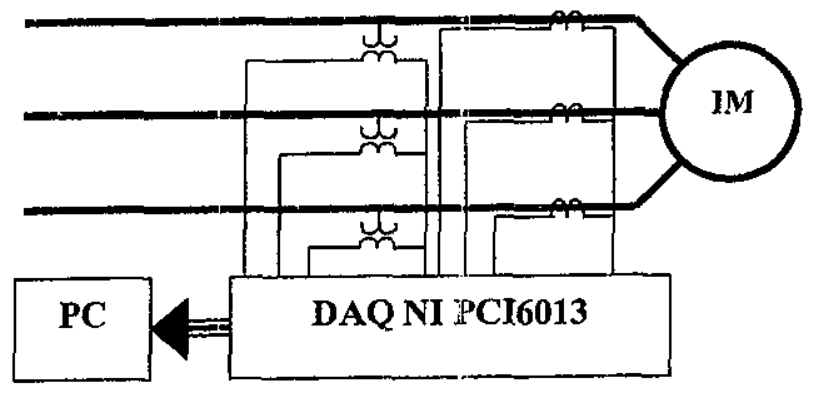

(a) Main Loop scheme

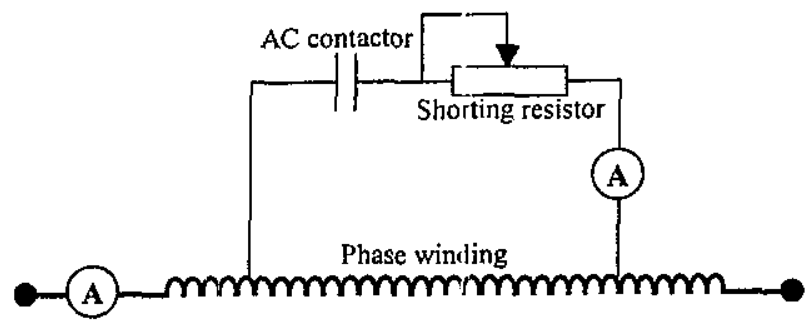

(b) Inter-turn short circuit loop scheme

Fig. 6 Experimental system Scheme

\section{SIMULATION RESULTS}

For fault detector net, only 297 cases are included in the training file. These cases belong to the healthy conditions and faulty conditions (with 0.01 of turns short circuited). The remainder of the collected cases are employed as a testing cases.

The output of the fault detector net is shown in Fig. 7 for fault occurrence with 0.005 of turns short circuited. It can be seen that the decision of the net gives correct classification. The effect of the percentage of faulty turns on the detector is shown in Fig. 8. This figure illustrates that, the larger the torns short-circuited, the faster the risponse of the detector.

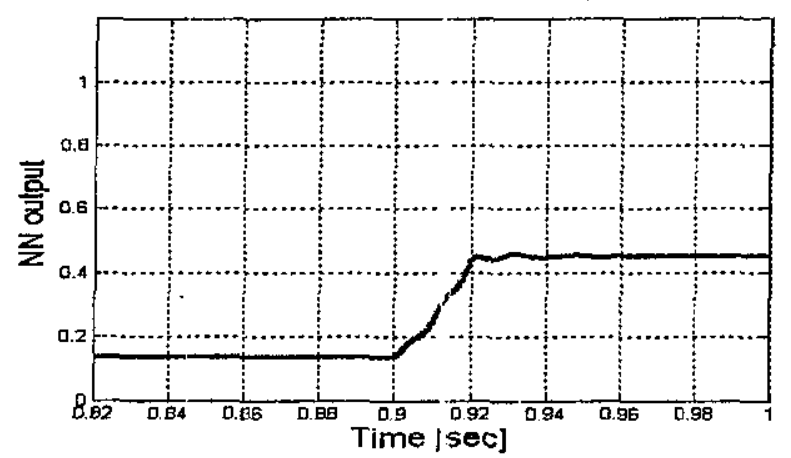

Fig. 7. The output of the fault detector NN for 0.005 of turns short circuit ocieurred at $0.9 \mathrm{sec}$ 


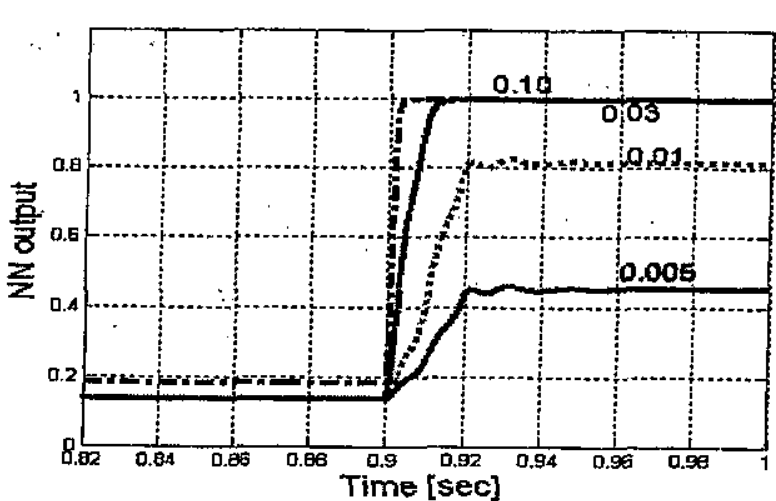

Fig. 8. The output of the fault detector NN for 0.005 , $0.01,0.03$, and 0.1 of turns short circuit occurred at $0.9 \mathrm{sec}$

A total number of 558 different faulted cases in various locations of the stator winding were used in order to train the ANN-based fault locator. In the aforementioned cases several percentage of turns short circuited (between $0.1 \%-10 \%$ ), load variation and distinct supply unbalance conditions were included. Concerning the pre-fault load current, three cases of pre-fault (No-load; Half-load; and Full-load) were chosen for the training process.

Fig. 9 and 10 illustrate the results obtained from fault locator net as the error in estimating percentage of the faulty turns against the actual percentage of the faulty turns for different percentage of unbalance in one and two phases.

These results show that, the errors obtained as unbalance in one or in two phases are nearly the same. The maximum error bounded between $-0.55 \%$ and $+0.55 \%$ and occurs at $0.5 \%$ and $10 \%$ of turns short circuit, Also it can be noted from these figures that, the least error occurs at nearly $1.5 \%, 5 \%$ and $8 \%$. Beyond these percentages, the error increases to maximum value of $0.4 \%$.

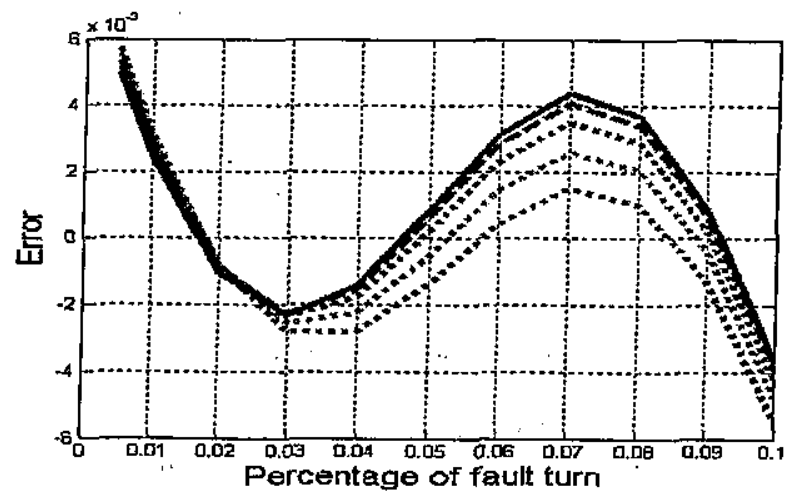

Fig. 9. The output of the fault locator NN for unbalance in one phase

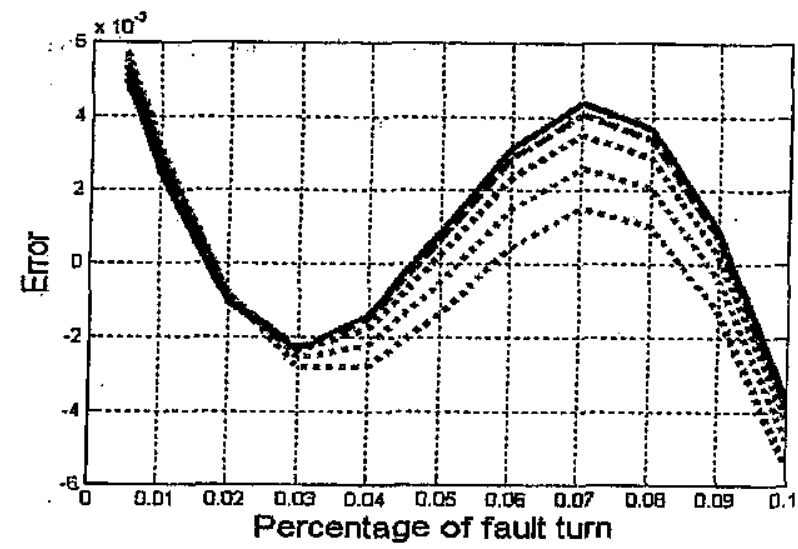

Fig. 10. The output of the fault locator NN for unbalance in two phases

\section{CONCLUSTON}

In this work, a proposed fault detection and location determination method, based on ANN techniques applied for identification of winding inter-turn shorts of induction motors has been presented. The location of fault "percentage of shorted turns" has a substantial effect on increasing the visibility of fault signature. The error obtained in fault location determination is not affected by the unbalance in one phase or in two phases but it is affected by the percentage of unbalanced. The proposed method need not motor parameters and is not affected by motor imperfections or supply unbalance. In this method a steady output from the fault detector is obtained in $20 \mathrm{msec}$ or less, initiated from the instant of fault occurrence.

\section{REFERENCES}

[1] Austin H. Bonnett and George C. Soukup, "Cause and Analysis of Stator and Rotor Failures in Three-Phase Squirrel-Cage Induction Motors", IEEE Transaction on Industry Applications, Vol. 28, No. 4, 1992.

[2] C. Gerada, K. J. Bradley, M. Sumner, P. Wheeler, S. Pickering, J. Clare, C. Whitley, and G. Towers, "The Implications of Winding Faults in Induction Motor Drives", Proceedings of the IEEE $39^{\text {th }}$ IAS Annual Meeting, Seattle, Washington, 2004.

[3] E. Wiedenbrug, G. Frey, and J. Wilson, "Impulse Testing and Turn Insulation Deterioration in Electric Motors", IEEE Pulp and Paper Industry Technical Conference ' 03 , 2003.

[4] 3. Kohler JU, Sottile J, Trutt FC (1992) Alternatives for Assessing the Electrical Integrity of Induction Machine", IEEE Trans Ind Appl 25:1107-1117 
[5] Farag SF, Bartheld RG, Habetler TG (1996), "An Integrated On-Line Motor Protection System", IEEE Ind Appl Mag 2(2):21-26

[6] Kliman GB, Premelani WJ, Koeg RA, Hoeweler D (1996), "A New Approach to on-Line Turn Fault Detection in AC Motors", IEEE-IAS Annual Meeting, Vol 1. IEEE, New York, pp 687-693

[7] Cash MA, Habetler TG, Kliman GB (1997), "Insulation Failure Predication in Induction Machines Using Line-Neutral Voltages", IEEE Industry Applications Conference IAS 97 Vol 1. IEEE, New York, pp 208-212

[8] Joksimovic G, Penman J (2000), "The Detection of Inter-turn Short Circuits in the Stator Windings of Operating Motors", IEEE Trans Ind Electron 47:1078-1084

[9] Tallam RM, Habetler TG, Gritter DJ, Burton BH. Harley RG (2000), "Neural Network Based On-Line Stator Winding Turn Fault Detection for Induction Motors", IEEE Industry Applications Conference, Vol 1. IEEE, Atlanta, Ga., pp 375-380

[10] F. Filippetti, G. Franceschini, C. Tassoni and P. Vas, "Recent Developments Of Induction Motor Drives Fault Diagnosis Using AI Techniques",
Proceedings of the Annual Conference of the IEEE Industrial Electronıcs Society, vol. 4, pp. 1966-1973, 1998.

[11] B. K. Lin, "An Unsupervised Neural Network Fault Discriminating System Implementation for On-Line Condition Moniloring And Diagnostics of Induction Machines", Ph.D. Dissertation, School of Electricai and Computer Engineering, Georgia Institute of Teclinology, Atlanta, USA, 1998.

[12] T. Kohonen, "Self-Orgarizing Maps", Springer, 1995.

[13] Murty V.V.S.Yalla, "A Digital Multifunction Protective Relay", IEEE Transactions on Power Delivery, Vol. 7, No. 1, January 1992, pp. 193200.

[14] G. Benmouyal, "Removal of DC Offset in Current Waveforms Using Digital Mimic Filtering", IEEE trans. on power Delivery, Vol. 10, No. 2, April 1995, pp 621 630.

[15] A. I. Taalab, H. A. Darwish, and T. A. Kawady, "ANN-Based Novel Fault Detector For Generator Windings Protection", IEEE Trans. Power Delivery, Vol. 14, No. 3, July 1999

[16] Arun G. Phadke, "Computer Relaying", Prantice Hell, 1992

\section{APPENDIX}

Table 1: Healthy and Faulty cases

\begin{tabular}{|c|c|c|c|c|}
\hline \multirow{3}{*}{$\begin{array}{l}\text { Percentage of } \\
\text { faulty turns }\end{array}$} & \multirow{3}{*}{ Load variation } & \multicolumn{3}{|c|}{ Number of cases } \\
\hline & & \multirow{2}{*}{ Supply balanced } & \multicolumn{2}{|c|}{ Supply unbalanced } \\
\hline & & & In one phase & In two phases \\
\hline \multirow{3}{*}{ Healthy case } & Full load & 1 & 5 & 25 \\
\hline & Half load & 1 & 5 & 25 \\
\hline & No load & 1 & 5 & 25 \\
\hline \multirow{3}{*}{$0.5 \%$} & Full load & 1 & 5 & 25 \\
\hline & Half load & 1 & 5 & 25 \\
\hline & No load & 1 & 5 & 25 \\
\hline \multicolumn{5}{|c|}{$\begin{array}{l}\text { Note that: } \\
\text { Cases of } 0.5 \% \text { are repeated for } 1 \%, 2 \%, 3 \%, \ldots \ldots, 10 \% \text { of turns short circuited } \\
\text { Total number of cases }=\underline{\mathbf{1 1 1 6}} \\
\underline{\mathbf{2 9 7}} \text { case are used for the training mode of fault detector } \\
\underline{\mathbf{5 5 8}} \text { case are used for the training mode of fault locator }\end{array}$} \\
\hline
\end{tabular}

